Article

\title{
Measuring Carbon Emissions of Pavement Construction in China
}

\author{
Youliang Huang ${ }^{1}$, Yan Ning ${ }^{1, *}$, Tao Zhang ${ }^{2}$ and Jiajie $\mathrm{Wu}^{3}$ \\ 1 Department of Construction and Real Estate, Southeast University, Nanjing 210096, China; \\ youliang_h@163.com \\ 2 Housing and Urban-Rural Development Bureau of Suzhou, Jiangsu 215002, China; geraldch@163.com \\ 3 State Grid Fujian Economic Research Institute, Fuzhou, 350012, China; w20051473@163.com \\ * Correspondence: ningyan@seu.edu.cn; Tel.: +86-258-379-3257 \\ Academic Editor: Andrew Kusiak \\ Received: 24 May 2016; Accepted: 25 July 2016; Published: 28 July 2016
}

\begin{abstract}
While various methodologies for quantifying carbon emissions of pavement construction are developed worldwide, adopting and promoting the existing tools to China's market is found fairly challenging due to institutional constraints. Therefore, the objectives of this study are to propose a methodology for measuring carbon emissions of pavement construction compatible with the fixed pricing systems prevalent in China; and develop an automatic tool for carbon estimations. The total carbon emissions are measured by aggregating emissions of energy consumption and materials used along with four stages, namely material manufacture, transportation, construction, and disposal. A set of composite carbon emission factors for energy and materials was calculated based on existing emission factors with the consideration of the boundaries concerned. The quantity of energy and materials used in pavement construction are obtained through bills of quantity and the fixed price system. The database of the emission factors for energy and materials was embedded into a C\# based tool, and validated in a real case.
\end{abstract}

Keywords: carbon emission calculation; pavement construction; China

\section{Background}

It is predicted that, by 2020, carbon emission of infrastructure projects in China will reach 0.197 billion tons [1]. Pavement construction is one of the significant contributors. According to the China Statistical Yearbook (2012), the numbers of municipal projects including pavement projects under construction and planned were 47097 and 30079, respectively in 2011 [2]; and these numbers are still increasing along with the rapid urbanization. To reduce carbon emissions, quantifying them is of significant importance. While various methodologies are available for quantifying carbon emission of pavement construction worldwide, adopting and promoting the existing tools to China's market is found to be fairly challenging due to the institutional constraints. Research widely recognized that carbon emission calculation varies across different countries due to difference associated with parameters, data source, construction methods and regional conditions [3,4]. This renders the comparison between different countries complex and difficult [4]. Another hindrance to carbon emission estimation for pavement construction is the scarcity of reliable data [5]. It is worth noting that, recently, Wang et al.'s (2015) and Ma et al.'s (2016) studies presented a list of carbon emission factors for pavement construction in China [6,7]. However, uptake of these factors would face challenges as practitioners have to collect a separate panel of data for the calculation methodology.

The objectives of this study are to develop a carbon emission calculation methodology with a customized database; and develop an automatic tool for carbon emission estimation. The customized database is compatible with the fixed pricing systems (Dinge) prevalent in China. Therefore, practitioners 
could calculate carbon emissions based on the bill of quantities which could be directly extracted from the project cost estimation software.

The structure of this paper is organized as follows. In Section 2, a literature review of tools for measuring carbon emissions of pavement construction is carried out, and their applicability to the China's context is discussed. Section 3 reports the proposed methodology and Section 4 focuses on developing specific parameters for the methodology application. Section 5 introduces a C\# based tool which embeds the proposed methodology and derived parameters. The methodology and the automatic tool are, in the end, validated in a real case in Section 6. The last section provides the conclusions and recommendations.

\section{Literature Review}

LCA tools for measuring carbon emissions are formalized by the International Organization for Standardization (ISO) 14040 series, particularly the ISO 14040:2006-Principles and Framework [8] and ISO 14044:2006-Requirements and Guidelines [9]. These two together describe the basic concepts and methodologies for LCA studies. For measuring carbon emissions of pavement projects, various practical tools have been developed. For instance, in 1997-1999, Euro bitume conducted an LCI study on paving grade bitumen. A new version in 2011 included polymer-modified binder and bitumen emulsion [10]. The bitumen LCI as a cradle to gate study covers: extraction of crude oil; transport to Europe including pipeline and ship transport; manufacturing of bitumen; and hot storage of the product. It also takes into account the construction of production facilities [10].

In 2011, UK Transport Research Laboratory, in collaboration with the Highways Agency, Mineral Products Association and Refined Bitumen Association, built an asphalt Pavement Embodied Carbon Tool (asPECT) [11]. This UK-based tool is able to produce PAS (Publicly Available Specification) 2050-compliant cradle-to-grave carbon footprint reports for asphalt [12]. The boundary covers: the cradle to gate $\mathrm{CO}_{2 \mathrm{e}}\left(\mathrm{CO}_{2}\right.$ equivalent) of each constituent material and ancillary material; the transport $\mathrm{CO}_{2 \mathrm{e}}$ from factory gate to plant; $\mathrm{CO}_{2 \mathrm{e}}$ arising from all forms of energy involved in producing the asphalt at the mixing plant, other than that involved in heating and drying, but including energy for offices on site; and $\mathrm{CO}_{2 \mathrm{e}}$ arising from the process of heating [11].

Huang et al. (2009) developed a spreadsheet-based LCA tool for construction and maintenance of asphalt pavements. The model consists of five worksheets. These are process parameters (e.g., energy in transportation), pavement parameters (e.g., pavement dimensions), unit inventory (i.e., energy production), project inventory (e.g., production process), and characterization results (e.g., global warming) [3].

International Road Federation designed a greenhouse gas calculator-Calculator for Harmonized Assessment and Normalization of Greenhouse-gas Emissions for Roads (CHANGER)—for road infrastructure projects. It is compatible with the International Panel on Climate Change (IPCC) guidelines and could be used to monitor and assess greenhouse gas emissions (GHG) generated during the different stages of the road construction process [13,14].

In 2007, Portland Cement Association published Environmental Life Cycle Inventory of Portland Cement Concrete, originally published in 2000 and updated in 2002 [15]. This report presents the results of the LCI of three concrete products, namely ready mixed concrete, concrete masonry, and precast concrete. The system boundary includes cement and slag cement manufacture, aggregate production, transportation of fuel, cement, supplementary cementitious materials, and aggregates to the concrete plant, and concrete plant operations [15].

Infrastructure Voluntary Evaluation Sustainability Tool (INVEST) was developed by the Federal Highway Administration. INVEST considers the lifecycle of projects and has three modules to evaluate the lifecycle of transportation services, including system planning, project development, and operations and maintenance. Each of these modules is based on a separate collection of criteria and can be evaluated separately [16]. 
Roadprint is an Excel-based tool, which can facilitate knowledge that will: implement pavement LCA in a standardized and reproducible manner; conduct probabilistic analysis; and generate well-analyzed presentations of results to interpret LCA outputs [17].

The BE2ST-in-Highways system incorporates standardized measurement methods of LCA and life-cycle cost analysis (LCCA) [18]. The system is equipped with a tool to weight sustainability indexes using the analytical hierarchy process and is embedded in an Excel spreadsheet. The evaluation steps include creating alternative pavement designs, predicting the service life of each design, identifying rehabilitation strategies, and conducting LCA and LCCA. Four criteria were considered in LCA: energy consumption, GHG emissions, water consumption, and generation of hazardous wastes. These four are defined by the U.S. Resource Conservation and Recovery Act.

Although various tools have been developed worldwide, it is widely recognized that a LCA model from one country cannot be simply applied to another due to difference between construction materials, construction techniques, and the validity and applicability of the data [3]. Yu and Lu (2012) argued that it seems impossible to perform straightforward comparison of the results due to the differences in approach, functional units, analysis periods, system boundaries, regional differences, and difference in input data [4]. Especially, the scarcity of reliable data would undermine the quality of carbon emission calculation [5]. Thus, for measuring carbon emissions of pavement construction in China, the methodology should be localized, with supporting database customized to the local context.

Ma et al. (2016) established an inventory analysis method to evaluate the greenhouse gas emissions from Portland cement concrete pavement construction in the west of China. The boundary of the concrete pavement construction process consists of raw material production, concrete manufacture, and pavement onsite construction. However, they failed to provide a transparent method to calculate the quantity of energy and material consumption. This might impede the uptake of this tool in practice [7].

In addition, Wang et al. (2015) estimated carbon emissions for three types of projects, namely subgrade, pavement, and bridges and tunnels [6]. The boundary comprises raw material production, material transportation, and onsite construction. They derived the material and energy consumption and machine working hours from the budget sheet. However, they did not provide evidence on scope match between emission factors and bill of quantities. For example, material wastes are often incurred on site, but might not be directly calculated in the carbon emission.

A lack of sufficient professionals in quantifying carbon emissions is another significant hindrance to the tool adoption. There is a huge deficiency of trained professionals in evaluating carbon emissions if the government is going to initiate carbon emission calculation or audit in road projects either in a voluntary or mandatory manner. The challenges to train a large group of professionals in a short term will be enormous. Thus, it will be more feasible to develop a methodology which is featured by labor-saving.

This study aimed to propose a methodology for measuring the carbon emissions of pavement construction compatible with the fixed pricing systems prevalent in China and develop a tool with built-in database of carbon emission factors to assist in the carbon estimations. This tool has the advantages of embedding a China contextualized database and being labor-saving.

\section{Quantifying Carbon Emissions of Road Construction Projects}

The boundary of carbon emission comprises four stages: material manufacture, transportation, construction, and disposal (see Equation (1))

$$
C E(S)=C E\left(S_{1}\right)+C E\left(S_{2}\right)+C E\left(S_{3}\right)+C E\left(S_{4}\right)
$$

where $C E\left(S_{1}\right)$ : Carbon emissions at the material manufacture stage; $C E\left(S_{2}\right)$ : Carbon emissions at the material transportation stage; $C E\left(S_{3}\right)$ : Carbon emissions at the construction stage; $C E\left(S_{4}\right)$ : Carbon emissions at the disposal stage. 
Equation (1) could be further converted in to the Equation (2) in accordance with the methodology shown in Figure 1. In the end, the total carbon emissions are aggregated under the energy consumption and materials used. For calculating Equation (2), quantity of energy consumption and material usage could be directly accessible by combing the bills of quantity and the fixed pricing system. The fixed price system in China is developed and maintained by the Ministry of Housing and Urban-Rural Development, China. The cost administration agency in each city and province could calibrate this system to its local context. This fixed price system has an authorized database for quantifying the material usage and energy consumptions. The database is updated on a regular basis. Therefore, the accuracy of calculating carbon emission could be guaranteed when it is designed to be compatible with the database.

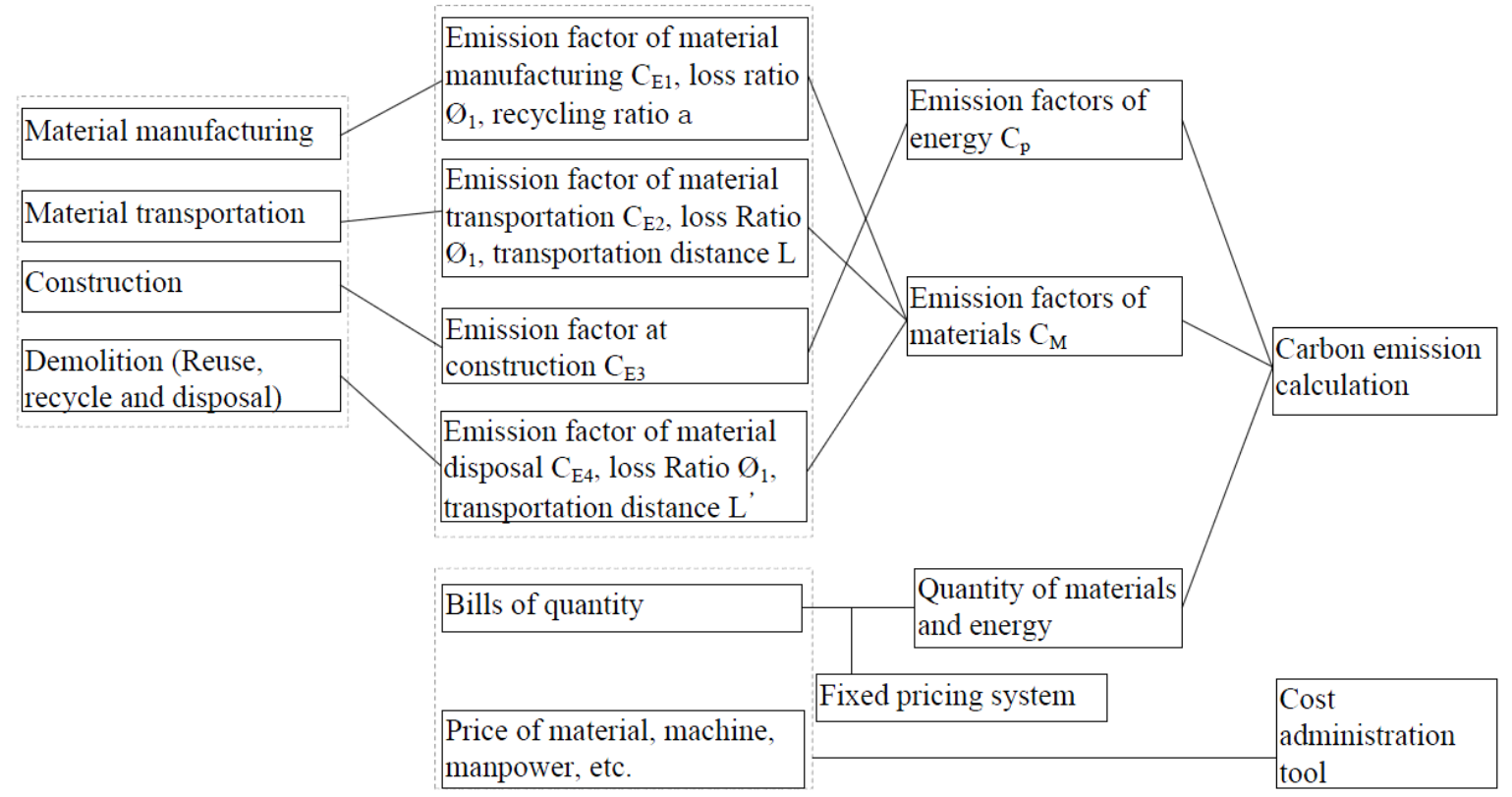

Figure 1. Framework for measuring carbon emission.

$$
\begin{aligned}
C E(S) & =C E\left(S_{1}\right)+C E\left(S_{2}\right)+C E\left(S_{3}\right)+C E\left(S_{4}\right) \\
& =\sum_{i}\left(1+\varphi_{1 i}\right) \times Q_{M i} \times C_{E 1_{i}}+\sum_{i}\left(1+\varphi_{1 i}\right) \times Q_{M i} \times C_{E 2_{i}} \\
& +\sum_{j} Q_{P j} \times C_{E 3_{j}}+\sum_{i} Q_{M i} \times \varphi_{1 i} \times C_{E 4_{i}} \\
& =\sum_{i}\left\{Q_{M i} \times\left(1+\varphi_{1 i}\right) \times\left[C_{E 1_{i}}+C_{E 2_{i}}+C_{E 4_{i}} \times \frac{\varphi_{1 i}}{\left(1+\varphi_{1 i}\right)}\right]\right\}+\sum_{j} Q_{P j} \times C_{E 3_{j}} \\
& =\sum_{i} Q_{M i}^{\prime} \times \widetilde{C}_{M i}+\sum_{j} Q_{E j} \times C_{P j}
\end{aligned}
$$

where $\widetilde{\mathrm{C}}_{M}$ : emission factors of materials; $Q_{M i}^{\prime}$ : quantities of materials (including wastes).

As can be seen from Equation (2) and Figure 1, two major steps of this methodology are to identify quantities of energy consumptions and material usage, and estimate a set of composite emission factors (i.e., $\widetilde{\mathrm{C}}_{M i}, C_{P}$ ) (see Figure 1). The first step could be easily completed by using the bill of quantity and the existing cost management system. The estimation of a set of composite emission factors is elaborated below.

The composite emission factors of materials $\left(\widetilde{C}_{M i}\right)$ are transformed from emission factors of material manufacturing $C_{E 1}$, material transportation $C_{E 2}$, material disposal $C_{E 4}$. The emission factor of energy $\left(C_{P}\right)$ is estimated from construction stage emission factors $\left(C_{E 3}\right)$. 


\subsection{Material Manufacture Stage}

At the material manufacture stage, the boundary of carbon emissions is defined from raw material to the final product, including energy use, transportation, and manufacturing process. Equation (3) is used to quantify carbon emission at the manufacture stage. Wastes during the construction are also taken into account.

$$
C E\left(S_{1}\right)=\sum_{i}\left(1+\varphi_{1 i}\right) \times Q_{M i} \times C_{E 1_{i}}
$$

where $Q_{M}$ : net quantity of material use; $C_{E 1}$ : emission factors of the material at the manufacture stage; $\varphi_{1}$ : percentage of wastes; $i$ : type of materials.

In Equation (3), the emission factors for the materials at the manufacture stage $C_{E 1}$ are calculated using Equations (4) and (5).

$$
C_{E 1}=\left(C_{m 1}+C_{m 2}+C_{m 3}\right) \times(1-\alpha)+s \times \alpha
$$

where $C_{m 1}$ : emission factors for the raw material manufacture; $C_{m 2}$ : emission factors for the raw material transportation; $C_{m 3}$ : emissions factors for energy use at the manufacture stage; $\alpha$ : percentage of material recycled; and s: emission factors for using the re-cycled material.

$$
C_{m 3}=\sum_{j} M_{P_{j}} \times C_{P_{j}}
$$

where

$$
C_{P_{j}}=C_{P_{j, k}} \times G W P_{k}
$$

where $M_{P}$ : energy consumption at the material manufacturing; $C_{P}$ : emission factors of stationary energy; $C_{P_{j, k}}$ : emission factors of type $k$ GHG for type $j$ energy; $G W P_{k}$ : GWP; $j$ : type of energy; $k$ : type of $\mathrm{GHG}$ (i.e., $\mathrm{CO}_{2}, \mathrm{CH}_{4}, \mathrm{~N}_{2} \mathrm{O}$ ).

\subsection{Material Transportation}

At the material transportation stage, energy consumption for transporting materials from the manufacture site to the construction site is the principal source of $\mathrm{CO}_{2 \mathrm{e}}$ emission. Carbon emission at the material transportation stage could be estimated by using Equation (6). The emission factors are calculated by using Equation (7). In Equation (7), $P \times C_{P}^{\prime}$ denotes the intensity of carbon emissions, with the unit of carbon emission per unit of material per unit distance.

$$
C E\left(S_{2}\right)=\sum_{i}\left(1+\varphi_{1 i}\right) \times Q_{M i} \times C_{E 2_{i}}
$$

where $Q_{M}$ : Net material use; $C_{E 2}$ : Emission factors of the materials at the transportation stage.

$$
\mathrm{C}_{E 2}=\sum_{j} L \times P_{j} \times C_{P_{j}}^{\prime}
$$

where

$$
C_{P_{j}}^{\prime}=\sum_{k} C_{P_{j, k}}^{\prime} \times G W P_{k}
$$

where $L$ : Distance from manufacture site to the construction site; $P$ : Energy consumptions per distance per unit of material; $C_{P}^{\prime}$ : Emission factors for the mobile source; $C_{P_{j, k}}^{\prime}$ : Emission factors of $k$ type GHG for $j$ type energy. 


\subsection{Construction Stage}

At the construction stage, $\mathrm{CO}_{2 \mathrm{e}}$ is mainly emitted from the energy consumption (i.e., electricity, diesel, petroleum gas) in the machinery operation. Thus, the carbon emission could be quantified using Equations (8) and (9).

$$
C E\left(S_{3}\right)=\sum_{j} Q_{P j} \times C_{E 3_{j}}
$$

where $Q_{P}$ : Energy consumptions; $C_{E 3}$ : Emission factors during the construction stage; $j$ : types of energy.

$$
C_{M 3}=\sum_{j} C_{P_{j, k}} \times G W P_{k}
$$

where $C_{P_{j, k}}$ : Emission factors of type $k$ GHG for type $j$ energy.

\subsection{Construction Waste Disposal Stage}

During the waste disposing stage, energy is consumed for transporting waste to landfill site. It is assumed that the vehicles are fully loaded and only one-way energy use is considered. It is also assumed that two recyclable materials are steel and aluminum given a high recycling ratio of these two materials. The equations are presented in Equations (10) and (11).

$$
C E\left(S_{4}\right)=\sum_{i} Q_{s i} \times C_{E 4 i}=\sum_{i} Q_{M i} \times \varphi_{1 i} \times C_{E 4 i}
$$

where $Q_{s}:$ quantity of waste; $C_{E 4}:$ emission factors of waste disposal.

$$
\mathrm{C}_{E 4}=\sum_{j} L^{\prime} \times P_{j} \times C_{P_{j}}^{\prime}
$$

where $L^{\prime}$ : the distance from the construction site to the landfill site; $C_{P}^{\prime}$ : emission factors for mobile sources.

\section{Parameters in the Methodology}

Using the methodology and equations presented in Section 3, this section aims to calculate three types of parameters, namely basic parameters (e.g., disposal transportation distance, recycling ratio), emission factors for energy and materials. When identifying these three types of parameters, the data source is preferred in the order of publications from public agencies, technical papers published by institutions, and academic findings in China.

\subsection{Basic Parameters}

Three types of basic parameters are presented in Table 1. Given a high recycling ratio of steel and aluminum, only these two materials are assumed to be recycled. Material losses during the stack at the site, re-processing, and construction are also taken into account. Besides, it is assumed that the transportation distance for the waste disposal $\left(L^{\prime}\right)$ is $50 \mathrm{~km}[19]$. 
Table 1. Basic parameters and their descriptions.

\begin{tabular}{ccc}
\hline Basic Parameters & Descriptions & Source \\
\hline \multirow{2}{*}{ Recycling ratio } & Section steel: 0.9 & \\
& Steel bar: 0.5 & {$[20]$} \\
& Aluminum: 0.95 & \\
& Steel: 6 & \\
Percentage of material waste (\%) & Cement: 2 & \\
& Concrete: 1.5 & {$[21]$} \\
& Sand: 3 & \\
& Gravel: 3 & \\
\hline & Cement: 100 & \\
& Steel: 125 & \\
Transportation distance $(\mathrm{km})$ & Sand and gravel: 200 & \\
& Timber: 80 & \\
& Brick: 50 & \\
\end{tabular}

\subsection{Emission Factors for Energy}

This study adopts $\mathrm{CO}_{2} \mathrm{e}$ to represent three types of GHG (i.e., $\mathrm{CO}_{2}, \mathrm{CH}_{4}$ and $\mathrm{N}_{2} \mathrm{O}$ ). The Global Warming Potentials (GWP) are adopted from [22]. Only electricity and fuel consumption are taken in to account. Emission factor for electricity $(0.816 \mathrm{~kg} / \mathrm{Kwh})$ is adopted from [23], which is locally available for the Jiangsu Province where the selected case is located.

Both stationary and mobile fuels are consumed in the road construction. Given a lack of authorized database of emission factors for fuel consumptions in China, the database provided by the IPCC (2006) was adopted [24]. This dataset was also previously used by the Chinese Government [25]. Under the IPCC,

Carbon emissisons from energy combusitions $=$ Combustion acitivity $(\mathrm{TJ}) \times$ emission factors $\left(\frac{\mathrm{kg}}{\mathrm{TJ}}\right)$

As the unit of TJ is not commonly used in China, a further transformation was carried out as follows.

$$
\begin{aligned}
\text { Carbon emissions } & =\text { Combustion activitie (unit) } \times \text { emisson factor }\left(\frac{\mathrm{kg}}{\text { TJ }}\right) \times \text { fuel value }\left(\frac{\mathrm{kg}}{\mathrm{GJ}}\right) \\
& =\text { Combustion activities (unit) } \times \text { emission factors }_{\text {transformed }}\left(\frac{\mathrm{kg}}{\mathrm{unit}}\right)
\end{aligned}
$$

where emission factors $(\mathrm{kg} / \mathrm{TJ})$ were accessed from [24].

Using these equations, the emission factors for stationary and mobile fuels are obtained (see Tables 2 and 3).

Table 2. Emission factors for stationary fuels $\left(C_{P}\right)$.

\begin{tabular}{ccccc}
\hline \multirow{2}{*}{ Types of Fuels } & \multirow{2}{*}{ Unit } & $\mathbf{C O}_{\mathbf{2}}$ Emission Factors & $\mathbf{C H}_{\mathbf{4}}$ Emission Factors & $\mathbf{N}_{\mathbf{2}} \mathbf{O}$ Emission Factors \\
\cline { 3 - 5 } & & $\mathbf{k g} / \mathbf{u n i t}$ & $\mathbf{k g} / \mathbf{u n i t}$ & $\mathbf{k g} / \mathbf{u n i t}$ \\
\hline Raw coal & $\mathrm{kg}$ & 1.825 & $6.27 \times 10^{-6}$ & $1.05 \times 10^{-5}$ \\
Other coals & $\mathrm{kg}$ & 0.730 & $2.51 \times 10^{-5}$ & $4.18 \times 10^{-6}$ \\
Coke oven gas & $\mathrm{m}^{3}$ & 0.624 & $5.02 \times 10^{-5}$ & $5.02 \times 10^{-7}$ \\
Other oven gas & $\mathrm{m}^{3}$ & 0.195 & $1.57 \times 10^{-5}$ & $1.57 \times 10^{-7}$ \\
Crude oil & $\mathrm{kg}$ & 2.973 & $4.18 \times 10^{-5}$ & $8.36 \times 10^{-6}$ \\
Petrol & $\mathrm{kg}$ & 2.907 & $4.31 \times 10^{-5}$ & $8.61 \times 10^{-6}$ \\
Diesel & $\mathrm{kg}$ & 3.097 & $4.27 \times 10^{-5}$ & $8.53 \times 10^{-6}$ \\
Fuel oil & $\mathrm{kg}$ & 3.157 & $4.18 \times 10^{-5}$ & $8.36 \times 10^{-6}$ \\
Liquefied petroleum gases & $\mathrm{m}^{3}$ & 2.114 & $1.17 \times 10^{-5}$ & $1.17 \times 10^{-6}$ \\
Other petroleum product & $\mathrm{kg}$ & 3.019 & $4.18 \times 10^{-5}$ & $8.36 \times 10^{-6}$ \\
\hline
\end{tabular}


Table 3. Emission factors for mobile fuels $\left(C_{P}^{\prime}\right)$.

\begin{tabular}{cccccc}
\hline \multirow{2}{*}{ Types of Fuels } & \multirow{2}{*}{ Unit } & \multicolumn{3}{c}{ Emission Factors $(\mathbf{k g} / \mathrm{TJ})$} & \multirow{2}{*}{ Carbon Emission Factors $C_{P}^{\prime}$ (kg/unit) } \\
\cline { 2 - 4 } & & $\mathbf{C O}_{\mathbf{2}}$ & $\mathbf{C H}_{\mathbf{4}}$ & $\mathbf{N}_{\mathbf{2}} \mathbf{O}$ & \\
\hline Petrol & $\mathrm{kg}$ & 67,500 & 9.6 & 0.96 & 2.930 \\
Diesel & $\mathrm{kg}$ & 72,600 & 1.6 & 1.3 & 3.115 \\
\hline
\end{tabular}

\subsection{Emission Factors for Materials}

Emission factors for materials are aggregated from three sub-emission factors (i.e., $C_{E 1}$ at the manufacturing stage, $C_{E 2}$ at the transportation stage and $C_{E 4}$ at the waste disposal stage). The database of composite emission factors for materials is shown in Table 4 . The results were achieved through two-stage calculation.

Table 4. Database of emission factors for materials.

\begin{tabular}{|c|c|c|c|c|c|}
\hline \multirow{2}{*}{ Material } & \multirow{2}{*}{ Unit } & \multicolumn{4}{|c|}{ Emission Factors (kg/unit) } \\
\hline & & $C_{E 1}$ & $C_{E 2}$ & $C_{E 4}$ & $C_{M}$ \\
\hline Large reinforced steel ${ }^{*}$ & $t$ & 1172.361 & 22.118 & 22.118 & 1216.597 \\
\hline Medium-small reinforced steel * & $\mathrm{t}$ & 937.778 & 22.118 & 22.118 & 982.014 \\
\hline Wire rod * & $\mathrm{t}$ & 1753.446 & 22.118 & 22.118 & 1797.682 \\
\hline Hot-rolled strip steels * & $\mathrm{t}$ & 1840.822 & 22.118 & 22.118 & 1885.058 \\
\hline Cold-rolled strip steels * & $\mathrm{t}$ & 2336.323 & 22.118 & 22.118 & 2380.559 \\
\hline Cement 52.5 & $\mathrm{t}$ & 1246.282 & 17.695 & 8.847 & 1272.823 \\
\hline Cement 42.5 & $\mathrm{t}$ & 1094.972 & 17.695 & 8.847 & 1121.513 \\
\hline Cement 32.5 & $\mathrm{t}$ & 792.829 & 17.695 & 8.847 & 819.371 \\
\hline Lime & $\mathrm{t}$ & 1180.000 & 17.695 & 8.847 & 1206.542 \\
\hline Reinforced concrete C20 & $\mathrm{m}^{3}$ & 230.000 & 8.847 & 8.847 & 247.695 \\
\hline Reinforced concrete C25 & $\mathrm{m}^{3}$ & 250.000 & 8.847 & 8.847 & 267.695 \\
\hline Reinforced concrete C30 & $\mathrm{m}^{3}$ & 270.000 & 8.847 & 8.847 & 287.695 \\
\hline Reinforced concrete C35 & $\mathrm{m}^{3}$ & 290.000 & 8.847 & 8.847 & 307.695 \\
\hline Reinforced concrete C40 & $\mathrm{m}^{3}$ & 310.000 & 8.847 & 8.847 & 327.695 \\
\hline Reinforced concrete C50 & $\mathrm{m}^{3}$ & 350.000 & 8.847 & 8.847 & 367.695 \\
\hline Asphalt concrete & $\mathrm{t}$ & 29.000 & 8.847 & 8.847 & 46.695 \\
\hline Plastic pipe & $\mathrm{m}$ & 6.308 & 0.035 & 0.018 & 6.361 \\
\hline PVC pipe & $\mathrm{m}$ & 9.400 & 0.035 & 0.018 & 9.453 \\
\hline Glass & $\mathrm{t}$ & 1657.480 & 17.695 & 8.847 & 1684.022 \\
\hline Ceramics & $\mathrm{t}$ & 1400.000 & 18.579 & 8.847 & 1427.427 \\
\hline Aluminum * & $\mathrm{t}$ & 1020.000 & 17.695 & 17.695 & 1055.389 \\
\hline Brick & 1000 & 320.000 & 14.156 & 14.156 & 348.311 \\
\hline Timber & $\mathrm{t}$ & 200.000 & 14.156 & 8.847 & 223.003 \\
\hline Copper & $\mathrm{t}$ & 3800.000 & 17.695 & 8.847 & 3826.542 \\
\hline Coating & $\mathrm{t}$ & 2058.600 & 14.156 & 8.847 & 2081.603 \\
\hline Petroleum bitumen & $\mathrm{t}$ & 285.000 & 17.695 & 8.847 & 311.542 \\
\hline Emulsified bitumen & $\mathrm{t}$ & 211.000 & 17.695 & 8.847 & 237.542 \\
\hline Gravel and sand & $\mathrm{t}$ & 4.667 & 23.593 & 5.898 & 34.158 \\
\hline Acetylene & $\mathrm{t}$ & 3385.000 & 0.000 & 0.000 & 3385.000 \\
\hline
\end{tabular}

Note: *: recycling ratio is taken into account; Emission factors at the manufacturing stage $\left(C_{E 1}\right)$ are adopted from [26].

(1) Manufacture stage $\left(C_{E 1}\right)$

Emission factors for 29 materials are identified (see Table 4). To illustrate the methodology, the case of calculating $C_{E 1}$ for reinforced steels is elaborated below (see Table 5). $C_{E 1}$ for reinforced steels is calculated by aggregating emissions from manufacturing process and transportation and energy consumption by using Equations (4) and (5). Three types of GHG are taken into account, namely 
$\mathrm{CO}_{2}, \mathrm{CH}_{4}$, and $\mathrm{N}_{2} \mathrm{O}$. Gong (2004) provided the data inputs about emission factors for manufacturing processes [26]. Aggregating these three emission factors yields a $C_{E 1}$ for reinforced steels.

Table 5. Examples for calculating the emission factors for material manufacture.

\begin{tabular}{cccccc}
\hline \multirow{2}{*}{ Type of Steel } & Process & \multicolumn{3}{c}{ Emission Factors $\mathbf{( k g / t )}$} & \multirow{2}{*}{$C_{E 1} \mathbf{( k g / t )}$} \\
\cline { 3 - 5 } & & $\mathbf{C O}_{\mathbf{2}}$ & $\mathbf{C H}_{\mathbf{4}}$ & $\mathbf{N}_{\mathbf{2}} \mathbf{O}$ & \\
\hline \multirow{3}{*}{ Reinforced steel } & Energy use & 1880.556 & 0.014 & 0.007 & 1882.929 \\
& Manufacturing process & 611.700 & 225.000 & 2.030 & 6841.640 \\
& Raw material transportation & 109.970 & 0.002 & 0.002 & 110.617 \\
& Total & $\mathbf{2 6 0 2 . 2 2 6}$ & $\mathbf{2 2 5 . 0 1 7}$ & $\mathbf{2 . 0 3 9}$ & $\mathbf{8 8 3 5 . 1 8 6}$ \\
\hline
\end{tabular}

(2) Transportation $\left(C_{E 2}\right)$ and waste disposal $\left(C_{E 4}\right)$

It is assumed that, at the material transportation and final disposal stage, trucks are the principal transportation vehicle which consumes diesel. The emission intensity for transportation is shown in Table 6 and emission factors for steel transportation and disposal are presented in Table 7. Equations (6) and (7) are used to calculate these emission factors. Wang (2009) found that energy consumption at the disposal stage accounts for $20 \%-50 \%$ of the new material manufacturing [27]. Therefore, a mean value of $35 \%$ was adopted in this study.

Table 6. Emission intensity for transportation.

\begin{tabular}{cccccc}
\hline \multirow{2}{*}{$\begin{array}{c}\text { Methods for } \\
\text { Delivery }\end{array}$} & $\begin{array}{c}\text { Energy Consumptions } \\
\mathbf{k J} /(\mathbf{t} \cdot \mathbf{k m})\end{array}$ & \multicolumn{2}{c}{ Emission Factor for Mobile Fuels (kg/TJ) } & \multirow{2}{*}{$\begin{array}{c}\text { Emission Intensity } \\
\mathbf{~ k g} /(\mathbf{t} \cdot \mathbf{k m})\end{array}$} \\
\cline { 3 - 4 } & 3662 & $\mathbf{C O}_{\mathbf{2}}$ & $\mathbf{C H}_{\mathbf{4}}$ & $\mathbf{N}_{\mathbf{2}} \mathbf{O}$ & \\
\hline Petrol & 2423 & 67,500 & 9.6 & 0.96 & 0.249 \\
Diesel & 72,600 & 1.6 & 1.3 & 0.177 \\
\hline
\end{tabular}

Table 7. Emission factors for material transportation and material disposal transportation.

\begin{tabular}{|c|c|c|c|c|c|c|c|c|c|c|}
\hline \multirow[t]{2}{*}{ Categories } & \multirow{2}{*}{$\begin{array}{c}L \\
(\mathrm{~km})\end{array}$} & \multirow{2}{*}{$\begin{array}{c}L^{\prime} \\
(\mathbf{k m})\end{array}$} & \multicolumn{4}{|c|}{$\begin{array}{l}\text { Emission Factors for Material } \\
\text { Transportation }(\mathrm{kg} / \mathrm{t})\end{array}$} & \multicolumn{4}{|c|}{$\begin{array}{c}\text { Emission Factors for Material Waste } \\
\text { Disposal }(\mathrm{kg} / \mathrm{t})\end{array}$} \\
\hline & & & $\mathrm{CO}_{2}$ & $\mathrm{CH}_{4}$ & $\mathrm{~N}_{2} \mathrm{O}$ & $C_{E 2}$ & $\mathrm{CO}_{2}$ & $\mathrm{CH}_{4}$ & $\mathrm{~N}_{2} \mathrm{O}$ & $C_{E 4}$ \\
\hline Steel & 125 & 125 & 21.989 & $4.85 \times 10^{-4}$ & $3.94 \times 10^{-4}$ & 22.118 & 21.989 & $4.85 \times 10^{-4}$ & $3.94 \times 10^{-4}$ & 22.118 \\
\hline
\end{tabular}

\section{A C\# Based Tool for Carbon Emission Calculation}

This methodology was programmed into a tool with the help of C\# and Visual Studio 2010. This tool has multiple features. First, it is compatible with the outputs of all cost management software currently available in China. Thus, adoption of this tool would contribute to boost productivity of quantifying carbon emission. Second, the tool is user-friendly as it is designed with a similar interface to Microsoft Office. Third, the quantification process is transparent and verifiable, with the aid of a reliable database. In addition, the emission factors and associated basic parameters could be further fine-tuned to any specific project if following the methodology proposed in this study.

Besides the basic function of carbon emission estimation, this tool also produces project background reports, has the function of managing the database of emission factors, and generates a carbon emission report. The carbon emission report comprises the total carbon emission and breakdown of the carbon emission of each type of material and energy. All the functions are shown in Table 8. 
Table 8. Functions of the carbon emission calculation tool.

\begin{tabular}{cc}
\hline Category & Functions \\
\hline Basic information & $\begin{array}{c}\text { Project characteristics } \\
\text { Profile of the assessor }\end{array}$ \\
\hline Quantification of carbon emissions & $\begin{array}{c}\text { Data inputs } \\
\text { Automatic estimation }\end{array}$ \\
\hline Report generation & Carbon emission report \\
\hline Data base management & Data set edit \\
& Built-in dataset updates \\
\hline
\end{tabular}

Operating the tool includes four steps: coding the material types; specifying the unit of each type of materials; inputting the database of the composite emission factors; and inputting quantity of materials and energy consumption. As the tool is compatible with spreadsheet format data, users can use the spreadsheet to prepare the material codes, unit of the material, and emission factor database.

\section{Case Study}

In order to verify the effectiveness of the tool, a road project located in Suzhou city, Jiangsu province, China was examined. Another purpose of the case study is to reach an initial recognition of the intensity of carbon emissions in China's pavement construction. The structure of the road is shown in Figure 2. The project comprised road and affiliated drainage works and pedestrian roads. It was about $0.56 \mathrm{~km}$ long and $26 \mathrm{~m}$ wide, with four $3.75 \mathrm{~m}$ lanes, plus a $3.5 \mathrm{~m}$ bicycle lane and $2 \mathrm{~m}$ sidewalk on both sides.

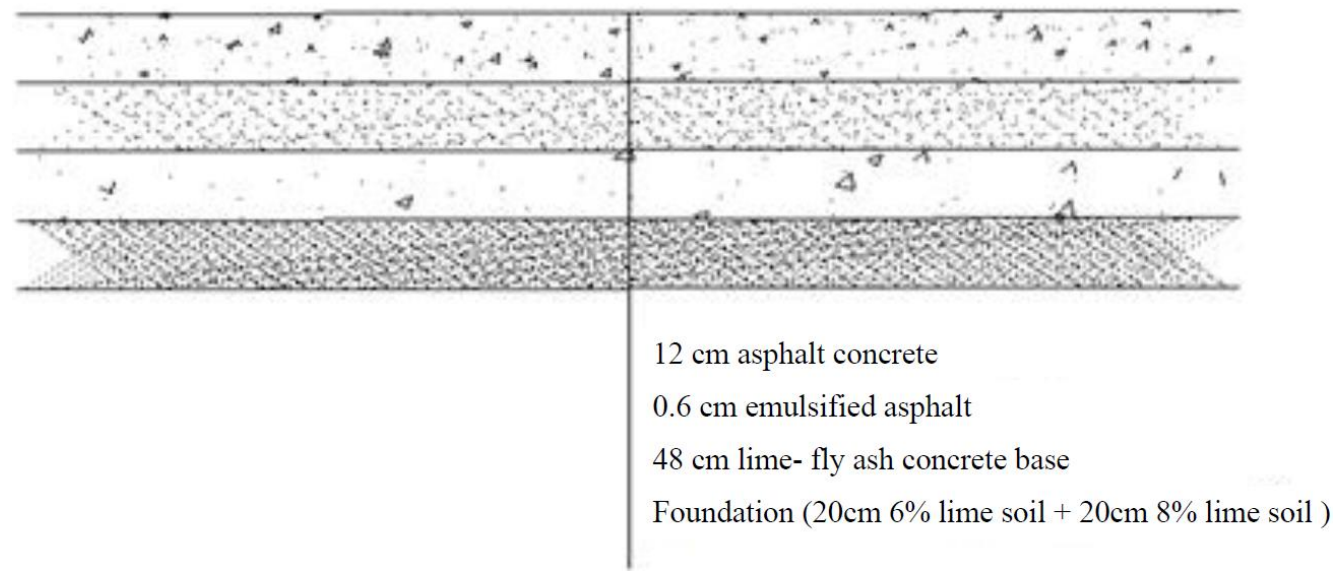

Figure 2. Structure of the pavement.

The boundary of carbon emission comprises material manufacture and transportation, construction, and construction waste disposal. The physical boundary contains construction of the road, affiliated drainage, and sidewalks. The functional unit is one-km four-lane road.

As shown in Figure 1, quantifying carbon emissions requires inputs of quantities of materials and energy consumptions and the composite emission factors. The quantities of materials were directly accessed from commercial software used for cost administration. In this case, it is "weilai qingdan". The mechanism for calculating the quantity of energy consumptions and material usage is based on the fixed pricing system, which is built in "weilai qingdan". The final results could be saved in a spreadsheet as an input for the carbon emission calculation.

The procedure of operating the tool consisted of creating a new project, inputting the list of quantity of materials and energy consumptions; selecting the emission factor for each type of materials; 
and clicking the calculation button. In the end, a report of carbon emission was obtained. For this case, the total carbon emission is $3744.457 \mathrm{t}$ (see Figure 3). Thus, the carbon emission per functional unit is $1672 \mathrm{t} /$ lane $\mathrm{km}$. The breakdown of carbon emissions shows that the use of lime accounts for $70 \%$ of the carbon emissions.

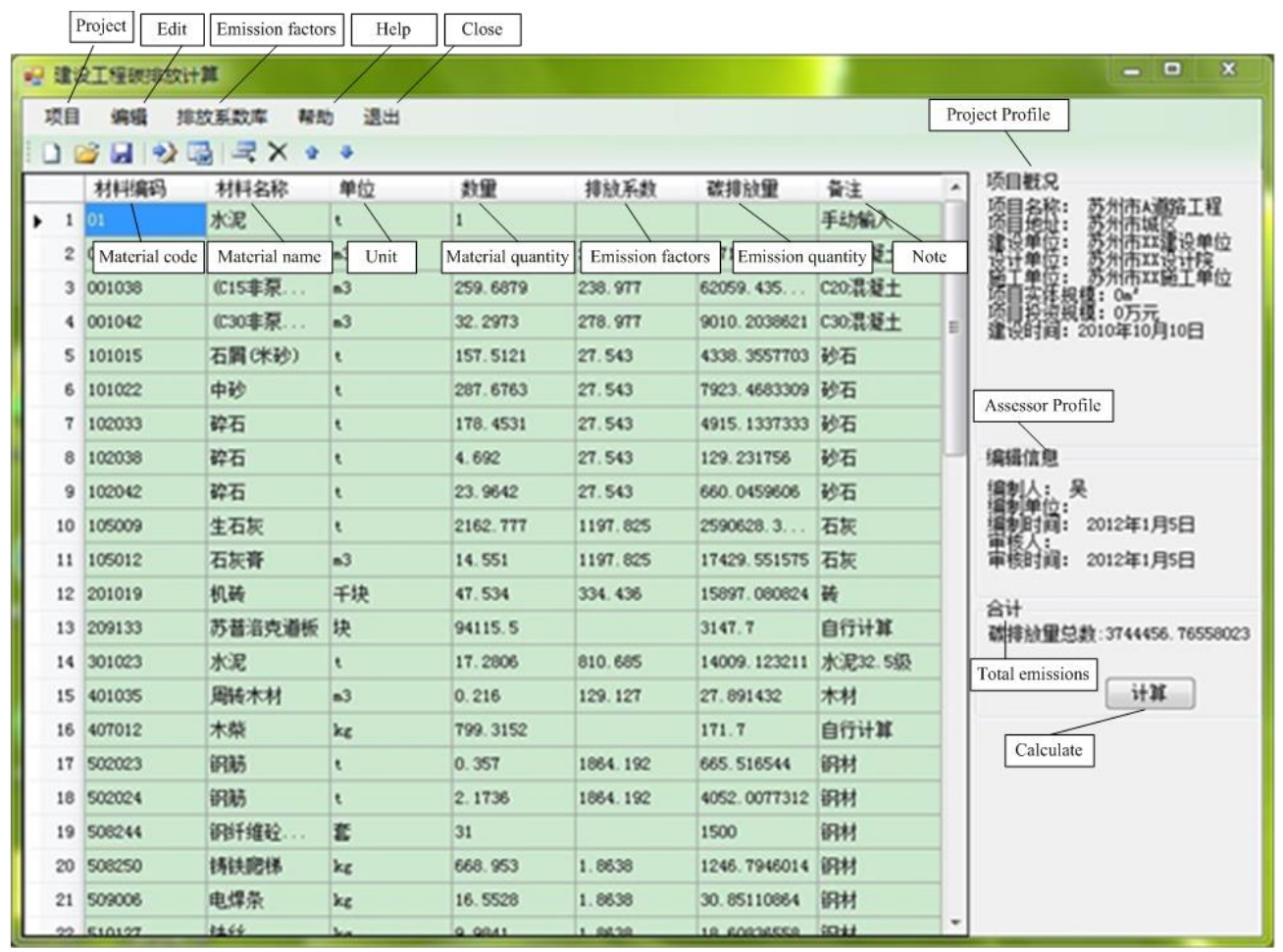

Figure 3. Carbon emission results.

\section{Conclusions and Recommendations}

While a number of methodologies for quantifying carbon emissions of road projects are developed in China and worldwide, adopting and promoting these tools to the China market is found fairly challenging due to the institutional constraints. To fill in this knowledge gap, a carbon emission calculation methodology compatible with the current fixed pricing systems used in China was proposed in this study. This methodology was programmed into a C\# and Visual 2010-based tool and further validated in a real case.

This study contributes to the extant literature by presenting a carbon emission calculation tool customized to the China's context. This tool developed was proven to be user-friendly through the case study. The methodology underpinning the practical tool could generate a reliable database, thereby ensuring accurate carbon emission quantification. The proposed methodology and tool also have advantages of facilitating the uptake as the quantity of the material and energy consumption could be directly obtained from the existing cost management software. This tool provides practitioners with an accurate and user-friendly platform to estimate carbon emissions of pavement construction. Besides, this study established a database of composite emissions factors for energy and materials for the Jiangsu Province context.

Generalizing such methodology to other countries or regions should be read with caution as the advantage of such a tool is its compatibility with the fixed pricing system in China and the emission factors are suitable for the Jiangsu Province context. However, this limitation is not unique to this study given that the boundary and methodology used in carbon calculation tools are expected to be compliant with the existing regulations and policy. The regulations and policy would vary considerably across geographic regions. 
Another limitation is that this study did not consider the carbon emission from operation and maintenance stages. Thus, for future studies, adopting an LCA approach is suggested (see life cycle approach in [28-30]). In addition, the environmental impact of pavement construction, other than the carbon emissions, could be incorporated in the LCA (see $[28,30])$. The emission factors for 29 types of materials and energy were identified in this study. Although most of them are the major materials in construction, they only constitute a small proportion of construction materials. Nonetheless, the methodology used in this study is applicable for calculating emission factors for other types of materials. Thus, future studies that enlarge this database are recommended.

The third limitation is concerned with the effects of concrete on carbon emission. This study mainly focused on the concrete which contributes to carbon emission. However, increasing studies found that high performance concrete would expand their lifespan and generate less carbon emissions (e.g., [31,32]). Thus, future studies that examine different types of concrete should take the variation of carbon emission factors into account.

This study assumed that all data source and input parameters are fixed across different project types. However, this assumption might not hold true as data sources and input parameters are subject to various uncertainties (see [28]). Thus, future studies that examine the uncertainty effect of the key data sources and input parameters would be suggested.

The last limitation is the simplification of concrete structure demolition. This study only takes the transportation of waste during the disposal stage into account. Existing studies found that extra carbon emission could also be generated during the disposal stage (see [33]). Future studies that present a holistic approach to investigate the carbon emissions during the disposal stage would be recommended.

Acknowledgments: Reviewers' constructive comments are acknowledged with many thanks. This research was supported by the National Science Foundation of China (71502032), the National Social Science foundation, China (12BJY021), the Fundamental Research Funds for the Central Universities and the Priority Academic Program Development of Jiangsu Higher Education Institutions.

Author Contributions: Youliang Huang and Tao Zhang conceived and designed the study; Jiajie Wu performed the data collection; Yan Ning and Jiajie Wu analyzed the data; Tao Zhang and Jiajie Wu contributed programming; Youliang Huang and Yan Ning wrote the paper.

Conflicts of Interest: The authors declare no conflict of interest.

\section{References}

1. Zuang, G.; Zhang, W. Urbanization in China: The way to low carbon infrastructure development. Environ. Econ. 2004, 5, 39-43. (In Chinese)

2. National Bureau of Statistics of China. China Statistical Yearbook, 2011; China Statistics Press: Bejing, China, 2011. (In Chinese)

3. Huang, Y.; Bird, R.; Heidrich, O. Development of a life cycle assessment tool for construction and maintenance of asphalt pavements. J. Clean. Prod. 2009, 17, 283-296. [CrossRef]

4. Yu, B.; Lu, Q. Life cycle assessment of pavement: Methodology and case study. Transp. Res. Part D Transp. Environ. 2012, 17, 380-388. [CrossRef]

5. Josa, A.; Aguado, A.; Heino, A.; Byars, E.; Cardim, A. Comparative analysis of available life cycle inventories of cement in the EU. Cement Concr. Res. 2004, 3, 1313-1320. [CrossRef]

6. Wang, X.; Duan, Z.; Wu, L.; Yang, D. Estimation of carbon dioxide emission in highway construction: A case study in southwest region of China. J. Clean. Prod. 2015, 103, 705-714. [CrossRef]

7. Ma, F.; Sha, A.; Yang, P.; Huang, Y. The Greenhouse Gas Emission from Portland Cement Concrete Pavement Construction in China. Int. J. Environ. Res. Public Health 2016, 13, 632. [CrossRef] [PubMed]

8. ISO 14040. Environmental Management-Life-Cycle Assessment-Principles and Framework; International Organization for Standardization: Geneva, Switzerland, 2006.

9. ISO 14044. Environmental Management-Life Cycle Assessment—Requirements and Guidelines; International Organization for Standardization: Geneva, Switzerland, 2006. 
10. Blomberg, T.; Barnes, J.; Bernard, F.; Dewez, P.; Clerc, S.L.; Pfitzmann, M.; Porot, L.; Southern, M.; Taylor, R. Life Cycle Inventory: Bitumen; The European Bitumen Association: Brussels, Belgium, 2011.

11. Wayman, M.; Schiavi-Mellor, I.; Cordell, B. Protocol for the Calculation of Whole Life Cycle Greenhouse Gas Emissions Generated by Asphalt_-Part of the Asphalt Pavement Embodied Carbon Tool (asPECT); IHS Press: Norfolk, VA, USA, 2011.

12. Huang, Y.; Spray, A.; Parry, T. Sensitivity analysis of methodological choices in road pavement LCA. Int. J. Life Cycle Assess. 2012, 18, 93-101. [CrossRef]

13. IRF (International Road Federation). Calculator for Harmonised Assessment and Normalisation of Greenhouse gas Emissions for Roads; IRF: Alexandria, VA, USA, 2013.

14. Huang, Y.; Hakim, B.; Zammataro, S. Measuring the carbon footprint of road construction using CHANGER. Inter. J. Pavement Eng. 2013, 14, 590-600. [CrossRef]

15. Marceau, M.L.; Nisbet, M.A.; VanGeem, M.G. Life Cycle Inventory of Portland Cement Concrete; Portland Cement Association: Skokie, IL, USA, 2007.

16. FHWA Infrastructure Voluntary Evaluation Sustainability Tool. Available online: https://www. sustainablehighways.org/ (accessed on 12 July 2014).

17. Lin, Y.-Y. Eco-Decision Making for Pavement Construction Projects; University of Washington: Seattle, WA, USA, 2012.

18. Lee, J.; Edil, T.B.; Benson, C.H.; Tinjum, J.M. Building Environmentally and Economically Sustainable Transportation Infrastructure: Green Highway Rating System. J. Constr. Eng. Manag. 2013. [CrossRef]

19. Huang, Z. Life-Cycle Energy Assessment of Buildings: Modeling and Empirical Study; Tongji University: Shanghai, China, 2003. (In Chinese)

20. Green Olympic Building Research Group. Team Green Olympic Building Assessment System; China Architecture and Building Press: Beijing, China, 2003. (In Chinese)

21. Wang, S. Life-Cycle Energy Assessment of Residential Buildings in Cold Regions; Harbin Institute of Technology: Harbin, China, 2007. (In Chinese)

22. IPCC Climate Change 2007: Working Group I: The Physical Science Basis, Direct Global Warming Potentials. Available online: http://www.ipcc.ch/publications_and_data/ar4/wg1/en/ch2s2-10-2.html\#table-2-14 (accessed on 15 May 2007).

23. Zhang, T. Emissions Accounting Models and Low-Carbon Paths of Urban Infrastructure: A Study of Suzhou; Tongji University: Shanghai, China, 2013. (In Chinese)

24. IPCC. IPCC Guidelines for National Greenhouse Gas Inventories; Global Institute for Strategic Studies: Washington, DC, USA, 2006.

25. National Development and Reform Commission. District Carbon Emission Factors of Electricity. Available online: http:/ /cdm.cchina.gov.cn/WebSite/CDM/UpFile/File2720.pdf (accessed on 2 December 2010).

26. Gong, Z. Environmental Impact Assessment of Construction Materials; Tsinghua University: Beijing, China, 2004.

27. Wang, J. $\mathrm{CO}_{2}$ Emissions for Residential Buildings in China; Tsinghua University: Beijing, China, 2009. (In Chinese)

28. Noshadravan, A.; Wildnauer, M.; Gregory, J.; Kirchain, R. Comparative pavement life cycle assessment with parameter uncertainty. Transp. Res. Part D Transp. Environ. 2013, 25, 131-138. [CrossRef]

29. Park, K.; Hwang, Y.; Seo, S.; Seo, H. Quantitative assessment of environmental impacts on life cycle of highways. J. Constr. Eng. Manag. 2003, 129, 25-31. [CrossRef]

30. Santero, N.J.; Masanet, E.; Horvath, A. Life-cycle assessment of pavements. Part I: Critical review. Resour. Conserv. Recycl. 2011, 55, 801-809. [CrossRef]

31. García-Segura, T.; Alcalá, J.; García Segura, T.; Yepes, V.; Alcalá, J. Life cycle greenhouse gas emissions of blended cement concrete including carbonation and durability. Int. J. Life Cycle Assess. 2014, 19, 3-12. [CrossRef]

32. Hasanbeigi, A.; Price, L.; Lin, E. Emerging energy-efficiency and $\mathrm{CO}_{2}$ emission-reduction technologies for cement and concrete production: A technical review. Renew. Sustain. Energy Rev. 2012, 16, 6220-6238. [CrossRef]

33. Kashef-Haghighi, S.; Shao, Y.; Ghoshal, S. Mathematical modeling of $\mathrm{CO}_{2}$ uptake by concrete during accelerated carbonation curing. Cement Concr. Res. 2015, 67, 1-10. [CrossRef]

(C) 2016 by the authors; licensee MDPI, Basel, Switzerland. This article is an open access article distributed under the terms and conditions of the Creative Commons Attribution (CC-BY) license (http://creativecommons.org/licenses/by/4.0/). 